http://jmscr.igmpublication.org/home/ ISSN (e)-2347-176x ISSN (p) 2455-0450 crossref DOI: https://dx.doi.org/10.18535/jmscr/v9i2.30

\title{
Correlation of platelet indices with glycaemic control and vascular complications in diabetic patients in a tertiary Hospital based study
}

\author{
Authors \\ Dr Aparajita Sharma ${ }^{1 *}$, Dr Sunil Arora ${ }^{2}$, Dr Shivangi Singh ${ }^{3}$ \\ ${ }^{1}$ PG 3rd Year, Pathology Department, SGT University \\ ${ }^{2}$ Professor, Pathology Department, SGT University \\ ${ }^{3}$ PG 2nd Year, Pathology Department, SGT University \\ *Corresponding Author \\ Dr Aparajita Sharma
}

\begin{abstract}
Background: Diabetes Mellitus (DM) is a group of metabolic disorders, characterised by chronic hyperglycaemia, metabolic abnormalities which lead to multiple complications ${ }^{1}$.Mean Platelet Volume $(M P V)$ and Platelet Distribution Width (PDW) are related to platelet size, enzymatic activity and prothrombotic potential, these parameters are easily obtained by automated haematology analysers at a relatively low cost. This study was accordingly taken with the aim to correlate the platelet indices with glycosylated haemoglobin (HbAlc) levels and also to determine the correlation of the platelet indices with diabetic complications.

Methods: The present study was a comparative prospective study, conducted from march 2020 to September 2020 at the Pathology department, SGT Medical college, Gurugram during the period of seven months on 119 diabetic patients.

Results: The majority of patients were in the age group of 51-70 years. Most of the patients showed bad glycaemic control, out of 119 patients, 97 patients showed HbAlC to be more than $6.5 \%$. Fasting blood glucose in group with $\mathrm{HbAlC}<6.5 \%$ and in group with $\mathrm{HbAlC}>6.5 \%$ were $140.78 \pm 3.12 \mathrm{mg} / \mathrm{dl}$ and $178.34 \pm 11.95 \mathrm{mg} / \mathrm{dl}$ respectively, which was highly significant between the two groups with $p$-value 0.001. All the platelet indices (platelet count, PDW and MPV) were found to be raised in patients with HbAlC > $6.5 \%$. Value of mean FBG, mean platelet count, MPV between the two groups shows statistically significant difference in their $p$ value. Out of 119 patients, 90 patients were without any complications. Fasting blood glucose is raised in patients with diabetic complications and is statistically significant. Platelet count in diabetics with complication was found to be $2.79 \pm 0.46 \mathrm{lakh} / \mathrm{cumm}$ in comparison to the platelet count in diabetics without complications which was $2.69 \pm 0.65$ lakh/cumm and is not statistically significant.

Conclusion: Increased mean fasting blood glucose, mean platelet count and MPV show significant association with glycaemic control and mean fasting blood glucose and glycaemic control show significant association with vascular complication. During routine haematological analysis higher platelet indices can easily be recognised and antiplatelet treatment may prevent disease progression.

Keywords: Diabetes Mellitus, Platelet indices, MPV, PDW.
\end{abstract}




\section{Introduction}

Diabetes Mellitus (DM) is a group of metabolic disorders, characterised by chronic hyperglycaemia, metabolic abnormalities which lead to multiple complications, primarily vascular affecting both small and large vessels causing micro and macrovascular complications, or both ${ }^{1}$. Diabetes Mellitus is caused by insulin insufficiency leading to type $1 \mathrm{DM}$ or by insulin resistance leading to type $2 \mathrm{DM}$ or both. ${ }^{2}$ Long standing Diabetes Mellitus is associated with mortality and morbidity resulting from complications caused by macrovascular disease and microvascular disease.

Macrovascular disease causes atherosclerosis which results in stroke, myocardial infarction, and lower extremity gangrene. Microvascular disease leads to diabetic retinopathy, nephropathy andneuropathy. 3,4

Diabetes is becoming a global pandemic disease due to adverse life style changes like reduced physical activity and excess calorie intake, the incidence of Diabetes Mellitus is increasing worldwide and will be more than doubled in 15 years. 5

Fasting Blood Glucose (FBG) and Haemoglobin A1c (HbA1c) are the parameters to monitor glycol-metabolic control. HbA1c (glycosylated haemoglobin) reflects average glycaemic exposure and indicates chronic glycaemia for threemonthsduration.HbA1c is a gold standard investigation in monitoring the disease and for initiating the treatment. HbA1c test however is not available in rural region because of limited laboratory resources. ${ }^{6}$

There is a vital role of platelets in the normal haemostasis. Platelets which are larger in size have higher thrombotic potential as they contain dense granules, which are metabolically and enzymatically more active than smaller platelets.

Mean Platelet Volume (MPV) and Platelet Distribution Width (PDW) are related to platelet size, enzymatic activity and prothrombotic potential. ${ }^{7}$ In the laboratory, these parameters are obtained by automated haematology analysers at a relatively low cost.

Various studies have reported that the haematological indices may be used as an indicator in diabetic patients developing vascular complications. ${ }^{8}$

This study was accordingly taken with the aim to correlate the platelet indices with glycosylated haemoglobin (HbA1c) levels and also to determine the correlation of the platelet indices with diabetic complications.

\section{Methods}

This comparative prospective study was conducted from March 2020 to September 2020 at the Pathology department, SGT Medical College, Gurugram during the period of seven months on 119 diabetic patients. All patients underwent a complete clinical evaluation with specific reference to macrovascular and microvascular complications. 2014 ADA criteria was used for diagnosing Diabetes Mellitus i.e. fasting blood glucose of $>126 \mathrm{mg} / \mathrm{dl}$ and $\mathrm{HbA} 1 \mathrm{c} \geq 6.5 \%$ were considered as diabetics.

\section{Inclusion Criteria}

Patients suffering from DM type II

\section{Exclusion Criteria}

Patients having anaemia, malignancy, chronic renal failure, cyanotic heart disease, inflammatory conditions (Rheumatoid arthritis, SLE), thrombocytopenia, thrombocytosis, diabetics on antiplatelet drugs, so as to rule out any other causes of reactive platelets.

After taking the detailed history and clinical examination of the patients, $2 \mathrm{~mL}$ blood was collected in two EDTA vacutainers, one was sent for platelet indices in automated haematology analyser another was sent for HBA1c estimation by high performance liquid chromatography method in Mindray BS-300. The sample for fasting blood glucose (FBG) was collected in sodium fluoride and estimated by automated biochemistry analyser (Mindray BS-300). 
Patients were divided into two groups, patients without diabetic complications $(90,75.64 \%)$ and patients with diabetic complications (29, 24.37\%). All diabetic patients were again divided on the basis of HBA1c levels, patients whose HBA1c is $<6.5 \%(22,18.49 \%)$ and patients with HBA1c $>6.5 \%(97,81.52 \%)$.

\section{Statistical Analysis}

Statistical package for the social sciences (SPSS) version 22 was used for analysing the data. Analysis of variance (ANOVA) was used to compare the variables. Data is expressed as mean \pm standard deviation. The p-value was calculated for each parameter and the $\mathrm{p}$ value $<0.05$ is considered statistically significant. Student t-test was used for doing comparison between two variablesHbA1c $<6.5 \& \mathrm{HbA} 1 \mathrm{c}>6.5$ and diabetics with $\&$ without complications.

\section{Normal Range}

Mean platelet volume (MPV): 7.4-10.4 fL, Platelet Distribution Width (PDW): 9-14 fL, Fasting blood glucose (FBG): $<100 \mathrm{mg} / \mathrm{dL}$, HbA1c: $<6.5 \%^{9}$

\section{Results}

The study was conducted over a period of seven months. Out of 119 patients, 64 (54.63\%) were males and $54(45.38 \%)$ were females. The majority of patients were in the age group of 5170 years.

Depending on the glycaemic control all 119 diabetic patients were divided into two groups, one with $\mathrm{HbA} 1 \mathrm{Clessthan} 6.5 \%$ and another with HbA1C more than $6.5 \%$. Most of the patients showed bad glycaemic control, out of 119 patients, 97 patients showed HbA1C to be more than $6.5 \%$ and 22 patients showed $\mathrm{HbA} 1 \mathrm{c}$ value less than 6.5.Fasting blood glucose in group with $\mathrm{HbA} 1 \mathrm{C}<6.5 \%$ and in group with $\mathrm{HbA} 1 \mathrm{C}>6.5$ $\%$ were $140.78 \pm 3.12 \mathrm{mg} / \mathrm{dl}$ and $178.34 \pm 11.95$ $\mathrm{mg} / \mathrm{dl}$ respectively, which was highly significant between the two groups with p-value 0.001 .

All the platelet indices (platelet count, PDW and MPV) were found to be raised in patients with HbA1C $>6.5 \%$. Value of mean FBG, mean platelet count, MPV between the two groups shows statistically significant difference in their $\mathrm{p}$ value.

However, platelet distribution width does not show any significance between two groups with pvalue 0.3796 .

Out of 119 patients, 90 patients were without any complications and 29 patients with complications. Fasting blood glucose is raised in patients with diabetic complications and is statistically significant. Platelet count in diabetics with complication was found to be $2.79 \pm 0.46$ lakh/cumm in comparison to the platelet count in diabetics without complications which was $2.69 \pm 0.65 \mathrm{lakh} /$ cumm and is not statistically significant.

Value of mean Platelet Distribution width (PDW) does not show much difference in the two groups and are statistically not significant $(\mathrm{p}=0.7478$ and $\mathrm{t}=0.322$ ).

The Mean platelet volume is $10.69 \pm 0.28 \mathrm{fl}$ in diabetic group with vascular complications which is found to be raised in comparison to the group without vascular complications which is not statistically significant. $\mathrm{HbA1C}$ is higher in patients with diabetic complications than in patients without complications and is statistically significant.

Table 1 Age and gender distribution of diabetic patients

\begin{tabular}{|l|c|c|c|c|}
\hline Age group (in years) & No. of patients & Percentage & Male & Female \\
\hline $18-30$ & 03 & $2.52 \%$ & 2 & 1 \\
\hline $31-50$ & 33 & $27.74 \%$ & 18 & 15 \\
\hline $51-70$ & 54 & $45.38 \%$ & 30 & 24 \\
\hline$>70$ & 29 & $24.37 \%$ & 15 & 14 \\
\hline Total & 119 & $100 \%$ & $65(54.63 \%)$ & $54(45.38 \%)$ \\
\hline
\end{tabular}


Table 2 Correlation of different parameters in diabetics with $\mathrm{HbA} 1 \mathrm{C}<6.5$ and $\mathrm{HbA} 1 \mathrm{C}>6.5$

\begin{tabular}{|l|c|c|c|c|}
\hline & HbA1C $<6.5 \%$ & HbA1C $>6.5 \%$ & p-value & t-test \\
\hline 1) No. of patients & 22 & 97 & & \\
\hline 2) Mean fasting blood glucose & $140.78 \pm 3.12$ & $178.34 \pm 11.95$ & $<0.0001$ & 14.578 \\
\hline 3) Mean platelet count & $2.27 \pm 0.25$ & $2.83 \pm 0.62$ & 0.0001 & 4.149 \\
\hline 4)Platelet distribution width & $17.65 \pm 0.95$ & $18.8 \pm 6.08$ & 0.3796 & 0.882 \\
\hline 5) Mean of mean platelet volume & $8.35 \pm 0.53$ & $10.64 \pm 1.43$ & $<0.0001$ & 7.377 \\
\hline
\end{tabular}

Table 3 Correlation of different parameters in diabetics with and without complications

\begin{tabular}{|l|c|c|c|c|}
\hline & $\begin{array}{c}\text { Diabetic complications } \\
\text { present }\end{array}$ & $\begin{array}{c}\text { Diabetic complications } \\
\text { absent }\end{array}$ & p- value & t-test \\
\hline 1) No. of patients & 29 & 90 & & \\
\hline 2) Mean fasting blood glucose & $184.32 \pm 14.2$ & $165.51 \pm 10.97$ & $<0.0001$ & 7.451 \\
\hline 3) Mean Platelet count & $2.79 \pm 0.46$ & $2.69 \pm 0.65$ & 0.4441 & 0.768 \\
\hline 4)Platelet distribution width & $17.55 \pm 1.28$ & $17.17 \pm 6.29$ & 0.7478 & 0.322 \\
\hline 5) Mean of mean platelet volume & $10.69 \pm 0.28$ & $10.07 \pm 1.79$ & 0.0664 & 1.853 \\
\hline 6) HbA1C (\%) & $10.79 \pm 1.79$ & $8.31 \pm 1.21$ & $<0.0001$ & 8.470 \\
\hline
\end{tabular}

\section{Discussion}

Diabetes Mellitus is a group of metabolic disorders, characterised by high blood glucose levels, metabolic abnormalities causing multiple complications. The prevalence of Diabetes Mellitus is on the rise throughout the world. India with 69.1 million DM patients tops the list followed by China. Around 415 million people were diagnosed with diabetes in 2015 with a projected increase to 642 million by 2040 worldwide. $^{10}$

One of the best ways to estimate blood glucose levels in diabetes patients is the measurement of HbA1c (glycosylated haemoglobin). It gives a picture of glycaemic control over a period of 3 months. It is the standard diagnostic and prognostic marker used in type $2 \mathrm{DM}$. However, it is comparatively expensive and is not readily available in several rural hospitals in India.

DM is characterised by metabolic abnormalities involving multiple organs such as heart, nerves, eyes, Central nervous system, kidneys, gastrointestinal tract and blood vessels, leading to long-term complications owing to increased mortality and morbidity.

It is a prothrombic state, which is accompanied by inflammation and accelerated atherosclerosis. ${ }^{11}$ Even though aetiology of DM is multifactorial, platelet, especially large platelets play an important role in the pathogenesis of diabetes and the development of complications due to DM.
Immature, larger platelets and activated platelets due to the metabolic milieu in Diabetes Mellitus causes abnormal functions of platelet. All these factors are interlinked. ${ }^{12}$

Platelets are small discoid blood cells that participate in haemostasis. Hyperglycaemia, dyslipidaemia and oxidative stress in DM damage the vascular endothelium leading to adherence of platelets at the damaged site and activation which thereby promote thrombogenesis. Primary plug formation due to platelets seals the vascular defects and provides the required phospholipid surface for the recruited and activated coagulation factors. Stimuli generated by the endothelium of blood vessels causes changes in shape of platelets, adherence to subendothelial surfaces and secretion of the contents of intracellular organelles forming a thrombus. ${ }^{13}$ These pro-aggregatory stimuli include thrombin, collagen, epinephrine, ADP (dense storage granules), and thromboxane A2 (activated platelets).Thus, platelets may assume an important role in signalling of the development of advanced atherosclerosis in diabetes. ${ }^{14,15}$

Platelet functions are altered in DM. Stand alone, hyperglycaemia leads to platelet activation by several mechanisms like non enzymatic glycosylation \& protein kinase activation. ${ }^{8}$

In our study, the age of cases ranged from 18 to 85 years. There were $65(54.63 \%)$ males and54 $(45.38 \%)$ females. 
In our study, the mean platelet count was higher in the diabetic group with higher HbA1C (poor glycemic control) that was similar to the studies done by Demirtunc et al. ${ }^{16}$ and Zuberi et al. ${ }^{17}$ Other studies by Hekimsoy et al. ${ }^{18}$ had observed the opposite finding with lower platelet counts in the diabetic group. Hence, the platelet count could be dependent on several variables, that is, mean platelet survival, platelet production rate, and turnover rate in DM. In our study, MPV was significantly higher in diabetics with $\mathrm{HbA1c}$ levels $>6.5 \%$ than in diabetics with HbA1c levels $<6.5 \%$. HbA1c and MPV showed significant association, which was also seen in the study done by Demirtunc et al. ${ }^{16}$

MPV were higher in diabetic patients with microvascular complications and was not statistically significant. Higher values were also seen in the studies done by Ates et $\mathrm{al}^{19}$ and Papanas et $\mathrm{al}^{20}$. This suggested a role for the increased platelet activity in the pathogenesis of vascular complications. Studies done by Hekimsoy et al. ${ }^{18}$ and Demirtunc et al. ${ }^{16}$ MPV was not significantly different in subjects with diabetic complications from that of diabetics without complications. HbA1C was found to be higher in patients with complications than in patients without complications and was statistically significant.

Therefore, it may be concluded that good glycaemic control decreases the hyper activity of the platelet function and thus may prevent or delay possible diabetic vascular complications. The reason for a high number of diabetics with $\mathrm{HbA1c}$ levels $>6.5 \%$ in the current study might have been due to poor dietary practices and lack of knowledge regarding the diet and exercise regimens that ought to be followed in diabetics.

\section{Conclusion}

The larger platelets are one of the important risk factors for the development of atherosclerosis and are associated with vascular complication. Increased mean fasting blood glucose, mean platelet count and MPV show significant association with glycaemic control and mean fasting blood glucose and glycaemic control show significant association with vascular complication. During routine haematological analysis higher platelet indices can easily be recognised and antiplatelet treatment may prevent disease progression. Hence, platelet indices are readily available tool to assess the control of DM, progression of disease as well as thromboembolic events.

\section{Conflict of Interest: None \\ Source of Funding: None}

\section{References}

1. World Health Statistics 2012. Noncommunicable diseases: A major health challenge of the ${ }^{21 s t}$ century. Available from: http: //www.who.int/ gho/publications/world_health_statistics/E N_WHS2012_Full.pdf [last accessed on2014, Sep 26].

2. Longo, Fauci, Kasper, Hauser, Jameson, Loscalzo. Harrison,s Principles of internal medicine. 18th edition. New York: McGraw-Hill Professional;2015

3. Anirban M.K, Abbas and Aster $\mathrm{R}$ and Cotran Pathologic Basis of Disease: South Asia Edition. Vol 2. Chapter 24.The Endocrine System. Elsevier;2015:1105-20

4. Jabeen F, Rizvi HA, Aziz F, Wasti AZ. Hyperglycemic induced variations in Hematological Indices in Type 2 Diabetics. IJAR. 2013; 1(8): 322-34.

5. Zimmet P, Alberti KG, Shaw J. Global and social implication of the diabetes epidemics. Nature 2001;414:782-7.

6. Sherwani SI, Khan HA, Ekhzaimy A, Masood A, and Sakharkar MK. Significance of HbA1c test in Diagnosis and Prognopsis of Diabetic Patients. Biomark Insights 2016;11:95-104.

7. Bhanukumar M, Ramaswamy PKH, Peddi NK, Menon VB. Mean Platelet Volume and Platelet Distribution Width as Markers 
of Vascular Thrombosis in Type 2 Diabetes Mellitus. J Postgrad Med Edu Res 2016;50(3):127-131

8. Biadgo B, Melku M, Mekonnen Abebe S, Abebe M. Hematological indices and their correlation with fasting blood glucose level and anthropometric measurements in type 2 diabetes mellitus patients in Gondar, Northwest Ethiopia. Diabetes, Metabolic Syndrome and Obesity: Targets and Therapy 2016;9:91-9.

9. Dastjerdi MS, Emami T, Najafian A, Amini A. Mean platelet volume measurement, EDTA or citrate?. Hematology. 2006;11(5):317-9.

10. Kumar A, Goel MK, Jain RB, Khanna P, Chaudhary V. India towards diabetes control: key issues. Australas Med J 2013;6:524-31.

11. Jindal S, Gupta S, Gupta R, Kakkar A, Singh HV, Gupta K, et al. Platelet indices in diabetes mellitus: indicators of diabetes microvascular complications. Hematology. 2011;16(2):86-9.

12. Yngen M. Platelet hyperactivity in diabetes mellitus. Eur Cardio. 2005;1(1):16.

13. Mitchell RN, Kumar V, Abbas AK, Fausto $\mathrm{N}$, Aster JC. Hemodynamic Disorders, Thromboembolic Disease and Shock. Robbins and Cotran Pathologic Basis of Disease. 2010. 8th ed; p. 11134.

14. Angiolillo DJ, Fernandez-Ortiz A, Bernardo E, Ramàrez $C$, Sabate $M$, Jimenez-Quevedo P, et al. Platelet function profiles in patients with type 2 diabetes and coronary artery disease on combined aspirin and clopidogrel treatment. Diabetes 2005; 54:2430 5 .

15. Colwell JA, Nesto RW, The platelet in diabetes-focus on prevention of ischemic events. Diabetes Care 2003; 26:2181 8 .
16. Demirtunc R, Duman D, Basar M, Bilgi M, Teomete M, Garip T, The relationship between glycemic control and platelet activity in type 2 diabetes mellitus. J Diabetes Complications 2009; 23:89 94

17. Zuberi BF, Akhtar N, Afsar S, Comparison of mean platelet volume in patients with diabetes mellitus, impaired fasting glucose and non-diabetic subjects. Singapore Med J 2008; 49:114 6.

18. Hekimsoy Z, Payzinb B, Ornek T, Kandogan $G$, Mean platelet volume in Type 2 diabetic patients. J Diabetes Complications 2004; 18:173 6.

19. Ate $\AA \ddot{Y}$ O, Kiki I, Bilen H, Kele $\AA \ddot{Y} ~ M$, Koà§er I, Kulaà§o Ä Ÿlu DN, et al. Association of Mean Platelet Volume With The Degree of Retinopathy in Patients with Diabetes Mellitus. Eur J Gen Med 2009; 6:99 102.

20. Papanas N, Symeonidis G, Maltezos E, Mavridis G, Karavageli E, Vosnakidis T, et al. Mean platelet volume in patients with type 2 diabetes mellitus. Platelets 2004; 15:4758. 